\title{
Fokus på bara: en experimentell studie av svenska förstaspråksinlärare
}

\author{
Av Christian Waldmann \\ lärare vid institutionen för humaniora, Växjö universitet, och \\ doktorand i nordiska språk vid Lunds universitet
}

\section{Inledning}

Barn har en fantastisk förmåga att snabbt och under kort tid erövra ett modersmål. Redan vid födseln uppvisar barn viss språkförmåga. Studier visar att nyfödda med hjälp av rytm, eller mer preciserat med hjälp av vokalernas varierande längd, intensitet och höjd skiljer olika språk från varandra (Christophe \& Morton 1998; Dehaene-Lambertz \& Houston 1998; Mehler \& Christophe 1995; Mehler m.fl. 1996; Nazzi m.fl. 1998a). Andra studier visar att nyfödda förstår variation i accentuering och tonhöjd (Nazzi m.fl. 1998b; se även Dupoux m.fl. 1997) och att 6 månader gamla barn är känsliga för prosodiska gränser på satsnivå (Jusczyk m.fl. 1992 - refererad till i Dupoux m.fl. 1997) och att de skiljer på alla fonetiska kontraster som finns i mänskliga språk (se Guasti 2002 för en utförligare redovisning). Church (1987) hävdar att barn använder icke-kontrastiv prosodisk information för att strukturera talsignalen i fonologiska konstituenter, d.v.s. strukturera talsignalen i enheter bestående av ord (se även Frazier 1987). Detta resulterar så småningom i att barn i 6-månadersåldern börjar känna igen typiska ordformer i modersmålet, och att de i 9-månadersåldern är känsliga för fonetiska och fonotaktiska egenskaper i modersmålet. Morgan (1986) går steget längre och betonar prosodins viktiga roll i erövringen av grammatiska kategorier.

I en kort sammanfattning beskriver Bates m.fl. (2001) viktiga steg i ett barns språkerövring. Under de fyra första åren lär sig ett barn inte bara att förstå ord, producera ord och sätta samman ord utan också att följa modersmålets grammatiska regler. De första tecknen på ordförståelse kan skönjas mellan 8 och 10 månaders ålder och då främst i form av lämpliga svar på tilltal, avsked o.dyl. Ordproduktionen börjar någon månad senare, 11-13 månader, först som ritualiserade ljud för djurläten, objekt m.m., och senare som ord för objekt. Den s.k. ordspurten sätter in mellan 12 och 24 månaders ålder; barnets ordförråd ökar då i en svindlande takt. Förmågan att använda orden i det egna ordförrådet till att skapa nya, d.v.s. kombinera ord, uppstår under perioden 18-20 månader. Den grammatiska spurten sker i åldern 20-36 månader då barnet lär sig att använda modersmålets grammatiska system, t.ex. grammatiskt genus, passiv, finithet, tempus, ordföljd, relativer etc. Språkutvecklingen efter 3 års ålder skiljer sig från den tidiga genom att barnet nu försöker att tillägna sig diskursiva och pragmatiska regler för användningen av språket, som exempelvis regler för användning av passiv och för bruk av personliga pronomen samt innebörden av kontrastiv prosodisk information. I denna artikel presenterar jag resultatet av två experiment som genomförts för att undersöka barns tolkning av bara. Mer preciserat undersöker jag hur barn tolkar bara i entydiga och tvetydiga kontexter.

Studien är disponerad enligt följande: I avsnitt 2 visar jag att barn långt upp i åldrarna har svårigheter med att tolka pragmatisk information för att lösa tvetydigheter. I avsnitt 3 beskriver jag de syntaktiska och semantiska egenskaperna hos studieobjektet bara. Denna beskrivning i kombination med presentationen i avsnitt 2 mynnar ut i två hypoteser om hur barn väntas förstå bara i entydiga och tvetydiga kontexter. I avsnitt 4 presenterar jag först resultaten av två experiment som genomförts för att testa hypoteserna. Därefter diskuterar jag resultaten. Slutligen, i avsnitt 5 sammanfattar jag slutsatserna av studien. 


\section{Pragmatisk information och tvetydighet}

I sin sammanfattning av barns språkutveckling påpekar Bates m.fl. (2001) att den senare språkutvecklingen, d.v.s. efter 3-4 års ålder, skiljer sig väsentligt från den tidiga, d.v.s. fram till 3-4 års ålder. Den tidiga handlar om att barnet ska tillägna sig verktygen för att överhuvudtaget kunna förstå och producera grammatiskt korrekta satser. Den senare däremot handlar om diskursanpassning - att anpassa sina grammatiskt korrekta satser till talsituationen. Ett tecken på detta är att barn under denna period lär sig att användning av personliga pronomen kräver att referenten först fastställs i diskursen. Det barnet lär sig under denna period är således att ta hänsyn till samtalspartnerns förkunskaper om situationen. Bates m.fl. (2001) hänvisar till ett experiment som testade barns kunskaper i att välja rätt diates i rätt situation. Experimentet bestod av korta tecknade serier i vilka ett djur utförde en handling mot ett annat djur. Barnen uppmanades sedan att beskriva situationen utifrån det andra djurets (patientens) perspektiv, något som krävde en passivkonstruktion. I över $80 \%$ av fallen valde vuxna att producera passiv diates, medan 3 år gamla barn undvek passiv - trots att de kan producera den - och istället beskrev situationen med en annan konstruktion som dock korrekt intog det efterfrågade perspektivet.

På grund av sin bristande förmåga att tolka pragmatisk information har barn även problem med att tolka satser korrekt. Detta visar sig bl.a. vid kvantifiering i negerade satser (Gualmini 2003a, 2003b; Musolino 1998; Musolino \& Lidz under tryck; Musolino \& Lidz 2003).

Musolino (1998) undersökte hur 5-åringar tolkade satser som innehöll en kvantifierare och en negation; ett exempel med kvantifieraren every ges i (1).

\section{(1) Every horse didn't jump over the fence.}

Satsen i (1) möjliggör två tolkningar, en isomorfisk och en icke-isomorfisk.[1] Om every har räckvidd över not (every>not = isomorfisk) får vi tolkningen 'inga hästar hoppade över staketet', men om not har räckvidd över every (not>every = icke-isomorfisk) får vi tolkningen 'inte alla hästar hoppade över staketet'. Experimentet gick ut på att barnen skulle ta ställning till om satsen i (1) var en korrekt beskrivning av en situation där 3 hästar skulle hoppa över ett staket men bara 2 gjorde det. Kontexten utformades så att en ickeisomorfisk tolkning gjorde (1) sann eftersom inte alla hästar hoppade över, medan en isomorfisk tolkning gjorde (1) falsk eftersom några hästar hoppade över. Resultatet visade att 5-åringar avvisade satsen som en beskrivning av den aktuella kontexten eftersom några hästar hade hoppat över staketet, d.v.s. de föredrog den isomorfiska tolkningen. Vuxna däremot föredrog den icke-isomorfiska tolkningen och accepterade således satsen i (1) som en beskrivning av den experimentella situationen. Liknande resultat fick Musolino för satser som The detective didn't find some guys där barn föredrog den isomorfiska (=inga)[2] medan vuxna korrekt föredrog den icke-isomorfiska (=inte alla).

I ett försök att generalisera sina resultat konkluderade Musolino (1998:145): "...when syntactic scope and semantic scope do not coincide /.../ children's interpretations correlate with the interpretations determined by syntactic scope." Musolino betraktade isomorfism som en avgörande skillnad mellan vuxnas och barns språkliga kompetens.

Tanken att isomorfism är en kompetensskillnad mellan barn och vuxna har ifrågasatts av flera forskare (Musolino \& Lidz under tryck; Musolino \& Lidz 2003; Gualmini 2003a; Gualmini 2003b). Experimentresultat pekar nu snarare mot att det rör sig om en performansskillnad mellan barn och vuxna. Musolino \& Lidz (under tryck) upprepade Musolinos (1998) studie med samma resultat, men formulerade samtidigt hypotesen att Musolinos design inte tillgodosåg det pragmatiska villkoret att en negerad sats kräver en affirmativ kontext att kontrasteras mot: "...negation seems to require - or at least to strongly prefer - an affirmative context against which to operate" (Horn 1989:172). För att testa denna hypotes lät de 20 engelska barn $(5 ; 0-5 ; 11)[3]$ ta ställning till satsen i (2) som en 
beskrivning av en situation där alla hästar hoppar över en stock men där bara 2 hästar av 3 hoppar över ett staket.

(2) Every horse jumped over the log but/and every horse didn't jump over the fence.

Resultatet av experimentet med (2) visade en helt annan bild än experimenten utan den affirmativa kontexten; majoriteten av barnen föredrog den icke-isomorfiska tolkningen, något som vuxna också gjorde till 100 \%. Slutsatsen av studien är således att barn inte saknar vuxenkompetens - de har tillgång till icke-isomorfiska tolkningar - utan att skillnaden mellan barn och vuxna beror på att barn inte är lika känsliga för pragmatisk information som vuxna. I den mån barn inte tar hänsyn till pragmatisk information förlitar de sig på syntaktiska faktorer som isomorfism, något som ger upphov till skillnader mellan barn och vuxna. Barnets känslighet för pragmatisk information kan dock ökas genom att man förser dem med mer kontextuell information. Samma slutsats har dragits i flertalet studier (Gualmini 2003a; Gualmini 2003b; Gualmini m.fl. 2003; Musolino \& Lidz 2003; Trueswell m.fl. 1999).

Slutsatsen är att barn och vuxna har olika känslighet för pragmatisk information, något som ibland ger upphov till diskrepanser mellan barns och vuxnas tolkningspreferenser vid tvetydiga satser. Barn har bl.a. problem med att bygga upp kontrasterande set i minnet, något som visar sig i att de i kontexter med kvantifierare och negation föredrar en isomorfisk tolkning.

I nästa avsnitt ska vi först se på några syntaktiska och semantiska egenskaper hos bara. Därefter formuleras några hypoteser om barns tolkning av fokusdomänen hos bara.

\section{Syntaktiska och semantiska egenskaper hos bara}

I en preverbal position kan fokusoperatorn bara ha olika fokusdomäner, d.v.s. den är tvetydig. En syntaktisk restriktion är att fokusdomänen i ytstrukturen måste förekomma till höger om bara. Således kan ett mittfältsplacerat[4] bara i en sats med sammansatt tempus fokusera hela verbfrasen (VP-fokus), det direkta objektet (DO-fokus) eller det indirekta objektet (IO-fokus) men inte subjektet (SU-fokus). Detta visas tillsammans med de olika tolkningarna i (3); ogrammatiska tolkningar markeras med *.

(3) Pippi har bara kastat en boll till Annika.

a. Det enda Pippi gjorde var att kasta en boll till Annika (VP-fokus)

b. Det enda Pippi kastade till Annika var en boll (DO-fokus)

c. Den enda Pippi kastade en boll till var Annika (IO-fokus)

d. *Den enda som kastade en boll till Annika var Pippi (SU-fokus)

I en postverbal position däremot har bara tendensen att fokusera det element som följer direkt efter. Detta illustreras i (4) där vi har svårt att få någon annan tolkning än DO-fokus.

(4) Pippi kastade bara en boll till Annika.

Det enda Pippi kastade till Annika var en boll (DO-fokus)

Ett nödvändigt kriterium för att en sats med bara ska vara tvetydig är således att bara är placerat i mittfältet samt att satsen har ett sammansatt tempus (se 5 ovan). Ett annat nödvändigt kriterium är att satsen har neutral prosodi. Mörnsjö (1999) har undersökt svenskans prosodi och kommit fram till att det sista lexikala ordet uppbär den hårdaste accenten, s.k. fokal accent. Föregående lexikala ord har en mjukare accent, s.k. prefokal accent. Detta mönster tilldelas satser med neutral vid tolkning, d.v.s. tolkningen som svarar på frågan: "Vad händer?" Detta illustreras i (5) där fetstil markerar den fokala accenten. Exemplet är taget från Mörnsjö (1999:65). 


\section{(5) (Vad händer?) Jag ska arbeta ikväll.}

Med en neutral fokal accent blir således satsen i (3) ovan tvetydig, något som möjliggör de tre tolkningarna i a, b och c. Fokal accent får inte sammanblandas med kontrastiv betoning, vilken karakteriseras av en kraftfullare talenergi med resultatet att satsens tvetydighet försvinner (se Jackendoff 1972 för en diskussion om prosodisk information och satsers sanningsvärden). Enligt Lundström-Holmberg \& af Trampe (1987) har den kontrastiva betoningen till uppgift att signalera att diskursen omfattar flera möjliga alternativ men att just ett alternativ har valts. Beroende på var den kontrastiva betoningen placeras erhåller vi olika tolkningar. I (6a) har kontrastiv betoning placerats på det direkta objektet, något som endast möjliggör DO-tolkning, och i (6b) har kontrastiv betoning placerats på det indirekta objektet, något som endast möjliggör IO-tolkning. För att kunna tolka (6a) korrekt måste vi förstå att bollen är en av många saker i den kontextuella situationen som kunde ha kastats (t.ex. en boll, en spade och en hink), men som inte blev kastade, och att det var just bollen som valdes ur detta set och kastades till Annika. Motsvarande gäller för (6b).

(6) a. Pippi har bara kastat en BOLL till Annika.

b. Pippi har bara kastat en boll till ANNIKA.

Reinhart (1999) menar att man för att korrekt förstå kontrastiv betoning måste bygga upp det kontrasterande setet av alternativ utifrån kontexten samt välja det rätta alternativet ur detta set. Hon menar vidare att kontrastiv betoning medför en större belastning på arbetsminnet än neutral, fokal accent, eftersom ett kontrasterande set måste byggas upp i minnet. Hennes hypotes är därför att barn, vars arbetsminne inte har samma kapacitet som vuxnas, inte klarar av att bygga upp kontrasterande set. Denna tanke finner stöd i Musolino \& Lidz (under tryck) där det konstaterades att barn visade vuxen kompetens endast om det kontrasterande setet gavs direkt i kontexten. En annan hypotes Reinhart för fram är att barn, p.g.a. sitt begränsade arbetsminne, gissar om de blir satta i en situation där de måste bygga upp kontrasterande set i minnet, något som dock inte finner stöd i studierna av kvantifiering i negerade satser. Dessa visar snarare att barn i sådana fall väljer en isomorfisk tolkning.

Egenskaperna hos bara gör det möjligt att ställa upp några hypoteser för hur barn tolkar fokusdomänen hos bara. Den första hypotesen är således att barn och vuxna tolkar fokusdomänen hos bara på olika sätt i satser där ett element uppbär kontrastiv betoning. Om Reinhart (1999) har rätt kommer barn att uppvisa ett tolkningsmönster som tyder på att de chansar vid kontrastiv betoning, men om Musolino \& Lidz (under tryck) m.fl. har rätt kommer de helt enkelt att uppvisa samma tolkningsmönster vid kontrastiv betoning som vid neutral, fokal accent. Den andra hypotesen som jag vill testa är om barn och vuxna tolkar fokusdomänen hos bara på samma sätt i tvetydiga kontexter, d.v.s. där satser återges med neutral, fokal accent. Denna hypotes grundar jag på föreställningen att satser med neutral, fokal accent inte medför samma belastning på arbetsminnet som kontrastiv betoning. I nästa avsnitt presenteras en studie med två experiment som genomförts för att testa dessa hypoteser.

\section{Den experimentella studien}

I detta avsnitt presenteras först resultaten av två experiment (4.1), och därefter diskuteras resultaten (4.2).

\subsection{Experimenten}

För att testa hypoteserna ovan har jag genomfört två experiment där jag använder en metod som kallas Truth Value Judgement Task (TVJT) (Crain \& Thornton 1998). Ett TVJT kräver två forskare, en som berättar en historia för barnet och en som spelar en docka, i detta fall Nalle Puh.[5] I slutet av historien yttrar dockan en sats som beskriver hur dockan 
förstod berättelsen, och barnets uppgift blir att ta ställning till sanningshalten i dockans yttrande. I denna studie fick barnet höra en berättelse och se tillhörande illustrationer på en dator, och vid slutet av berättelsen fick barnet ta ställning till om Nalle Puhs beskrivning av berättelsen var korrekt eller inte. Nalle Puhs yttranden bestod antingen av tvetydiga eller entydiga satser, som de i (3) och (6) ovan. Experiment 1 utformades med villkoren NEUTRAL (neutral, fokal accent) och DO-FOKUS (kontrastiv betoning på direkt objekt), medan experiment 2 designades med villkoren NEUTRAL och IO-FOKUS (kontrastiv betoning på indirekt objekt). Varje experiment omfattade 4 yttranden av Nalle Puh varav 2 var neutrala och 2 var fokuserade samt en uppvärmningshistoria. Berättelserna utformades så att Nalle Puhs yttranden var sanna vid DO-tolkningen och falska vid IO- och VPtolkningen. Ett ja-svar motsvarade alltså DO-fokus, medan ett nej-svar motsvarade IOeller VP-fokus. För att skilja IO-tolkningen från VP-tolkningen förlitade jag mig på barnens motiveringar av svaren. Hypoteserna var att barn och vuxna föredrar samma tolkning i det neutrala villkoret samt att barn inte tolkar den kontrastiva betoningen i det fokuserade villkoret korrekt, men att vuxna föredrar DO-tolkningen i DO-FOKUS och IOtolkningen i IO-FOKUS.

För experiment 1 testade jag 30 barn med svenska som modersmål i åldrarna 3;6-6;10 samt 10 vuxna svenskar. Av de 30 barnen var jag tvungen att utesluta 9 eftersom de missförstod uppgiften eller tvekade med att svara. Resultaten av experiment 1 sammanfattas i tabell 1.

Tabell 1. Resultat av experiment 1

\begin{tabular}{|l|l|l|l|l|}
\hline \multirow{2}{*}{ Tolkning } & \multicolumn{2}{|c|}{ Barn } & \multicolumn{2}{c|}{ Vuxna } \\
\cline { 2 - 5 } & NEUTRAL & DO-FOKUS & NEUTRAL & DO-FOKUS \\
\hline DO & $81 \%(34)$ & $78,6 \%(33)$ & $70 \%(14)$ & $95 \%(19)$ \\
\hline IO & & & $15 \%(3)$ & $5 \%(1)$ \\
\hline VP & $9,5 \%(4)$ & $7,1 \%(3)$ & $15 \%(3)$ & \\
\hline Oklar & $9,5 \%(4)$ & $14,3 \%(6)$ & & \\
\hline
\end{tabular}

I tabell 1 kan vi se att både vuxna och barn föredrar DO-tolkningen i det neutrala villkoret. Barnen verkar i något större utsträckning än vuxna föredra DO-tolkning framför andra tolkningar (81 \% mot $70 \%$ ). Denna skillnad mellan barn och vuxna är dock inte särskilt stor, något som jag inte heller väntade mig eftersom hypotesen var att barn och vuxna föredrar samma tolkning vid neutral, fokal accent. Vi ser heller ingen skillnad mellan barns neutrala och fokuserade villkor (81 \% mot 78,6 \%). Däremot ser vi att vuxna använder den kontrastiva betoningen på det direkta objektet för att lösa tvetydigheten i det fokuserade villkoret (70 \% DO-tolkning i NEUTRAL mot 95 \% i DO-FOKUS). Vi kan också se en skillnad mellan barn och vuxna i det fokuserade villkoret där barn föredrar DO-tolkningen i 78,6 \% av fallen och där motsvarande siffra för vuxna är $95 \%$. Denna skillnad väntade vi oss eftersom hypotesen var att barn inte tolkar den kontrastiva betoningen korrekt, medan vuxna föredrar den tolkning som är kontextuellt motiverad. Sammanfattningsvis kan vi säga att barn tolkar fokusdomänen hos bara som vuxna vid neutral läsning. De avviker från vuxna om det direkta objektet har kontrastiv betoning; barn uppvisar samma tolkningspreferenser som vid neutral läsning medan vuxna väljer DO-tolkningen.

För experiment 2 testade jag 8 barn med svenska som modersmål i åldrarna 3;7-5;11 och 11 vuxna svenskar. 1 barn missförstod testet och uteslöts således. Resultaten av experiment 2 sammanfattas i tabell 2.

Tabell 2. Resultat av experiment 2

\begin{tabular}{|l|l|l|l|l|}
\hline \multirow{2}{*}{ Tolkning } & \multicolumn{2}{|c|}{ Barn } & \multicolumn{2}{c|}{ Vuxna } \\
\cline { 2 - 5 } & NEUTRAL & IO-FOKUS & NEUTRAL & IO-FOKUS \\
\hline DO & $92,9 \%(13)$ & $92,9 \%(13)$ & $100 \%(22)$ & $36,4 \%(8)$ \\
\hline IO & $7,1 \%(1)$ & & & $63,6 \%(14)$ \\
\hline
\end{tabular}




\begin{tabular}{|l|l|l|l|l|} 
VP & & & & \\
\hline Oklar & & $7,1 \%(1)$ & & \\
\hline
\end{tabular}

Liksom i tabell 1 kan vi i tabell 2 se att både barn och vuxna föredrar DO-tolkningen i det neutrala villkoret, 92,9\% mot $100 \%$. Dessutom ser vi ingen skillnad mellan barns neutrala och fokuserade villkor; de föredrar DO-tolkningen i 92,9 \% av fallen i båda villkoren. Däremot ser vi en klar skillnad mellan vuxnas neutrala och fokuserade villkor; det framgår tydligt att vuxna tolkar den kontrastiva betoningen (100\% DO-tolkning i NEUTRAL mot 36,4 \% DO-tolkning och 63,6 \% IO-tolkning i IO-FOKUS). Vi ser också en tydlig skillnad mellan barns och vuxnas fokuserade villkor. Något förvånande är dock att vuxnas svarsmönster i det fokuserade villkoret innefattar så mycket som 36,4 \% DO-tolkning. Det väntade resultatet var snarare 100 \% IO-tolkning. Detta tyder på en väldigt stark tolkningsstrategi att uppfatta det direkta objektet som fokusdomänen för bara, en strategi som inte helt kan kringgås med hjälp av kontrastiv betoning. Sammanfattningsvis kan sägas att detta experiment stöder resultaten från experiment 1: barn tolkar fokusdomänen hos bara som vuxna vid neutral läsning, och de uppvisar samma tolkningspreferenser vid kontrastivt betonat indirekt objekt som vid neutral läsning medan vuxna väljer IOtolkningen.

\subsection{Sammanfattande diskussion}

Mina resultat visar att barn långt upp i 6-7 årsåldern har svårt för att lösa tvetydigheter med hjälp av kontrastiv betoning, något som resulterar i att barn och vuxna föredrar olika tolkningar i det fokuserade villkoret. Liknande resultat presenteras i Gualmini m.fl. (2003), McDaniel \& Maxfield (1992) (refererad till i Gualmini m.fl. 2003), Reinhart (1999) och Szendrõi (2003). Om barns tillkortakommanden inom detta område beror på att deras arbetsminne är mer begränsat än vuxnas är omöjligt att avgöra på basis av denna studie. Min studie visar däremot inte att barnen gissar om de blir satta i en situation där de måste bygga upp kontrasterande set i minnet som Reinhart (1999) predicerar. Snarare verkar de följa samma tolkningsstrategi i både det neutrala och fokuserade villkoret, en strategi som leder till DO-tolkning (se även Gualmini m.fl. 2003). Dessutom, i en alldeles färsk undersökning av kontrastiv betoning på some visar Miller m.fl. (2004) att barn klart skiljer på some utan kontrastiv betoning och some med kontrastiv betoning, något som öppnar för hypotesen att barns förmåga att tolka kontrastiv betoning är lexikalt bunden. En annan spännande hypotes som följer direkt ur Musolino \& Lidz (under tryck) är att barns förmåga att tolka kontrastiv betoning kan underlättas om den kontextuella informationen ger det kontrasterande setet, istället för att barn måste bygga upp det i minnet. Framtida experiment får dock utvisa om dessa hypoteser kan bidra till mer förståelse om varför barn har problem att tolka kontrastiv betoning.

Frågan är då varför barn, och även vuxna i neutralt villkor, föredrar just DO-tolkningen. Den första tanken som slår mig är om de olika tolkningarna i det neutrala villkoret (DO-, IO- och VP-tolkning) hade lika stora chanser att bli valda, eller är det så att bara i större utsträckning tar en särskild typ av kategorier i sin fokusdomän. Detta har undersökts i Wijk-Andersson (1991). Hon kommer fram till att bara fokuserar ett element i verbfrasen däribland direkt och indirekt objekt - i 79,8 \% (1260/1579) av fallen och verbfrasen i 20,2 \% (319/1579) av fallen. En studie av två svenska barnkorpusar (Markus, 1;3.19-2;9.29 och Anton, 1;11.8-2;10.4) som återfinns i databasen CHILDES (Plunkett \& Strömqvist 1992; Strömqvist m.fl. 1993; MacWhinney 2000), där jag excerperat dels den input av fokusdomänen hos bara som barnen får av vuxna, dels barnens egen användning av bara, visar ungefär samma resultat som Wijk-Andersson (1991). Inputen fördelar sig enligt följande: VP-tolkning (24,7 \%, 19/77), element-i-VP-tolkning (59,7 \%, 46/77) och övrig tolkning, d.v.s. fokusdomäner bestående av hela satser, $(15,6 \%, 12 / 77)$. Och barnens egen användning fördelar sig enligt följande: VP-tolkning (35,3 \%, 6/17) och element-i-VPtolkning (64,7 \% 11/17). En närmare analys av element-i-VP-tolkningen visar att bara i $46,8 \%$ (36/77) fokuserar en nominalfras (s.k. NP-tolkning = direkt eller indirekt objekt) i inputen, och 52,9 \% (9/17) NP-tolkning i barnens produktion. Resultatet av korpusstudien 
visar att barn redan i 2-3-års åldern använder bara främst till att fokusera ett element i verbfrasen - och då främst en nominalfras - vilket stöder tanken om att VP-tolkningen i experimentet inte hade lika stor chans att bli vald.

Men även om vi kan diskvalificera VP-tolkningen på grundval av frekvens så kvarstår frågan varför DO-fokus valdes före IO-fokus. Gualmini m.fl. (2003) genomförde ett liknande experiment som i denna studie och kom fram till att engelska barn föredrog IOtolkningen, även i de fall där det direkta objektet uppbar kontrastiv betoning. Vad fick engelska barn att föredra IO-tolkning och svenska barn att föredra DO-tolkning? En gissning är att det rör sig om faktorer i experimentsituationen som gör att barn väljer det ena eller andra. Om aktörerna i berättelserna är intressanta och framträdande och därmed drar barnets uppmärksamhet till sig medan objekten står i bakgrunden kan detta leda till IO-fokus. Om förhållandet är det omvända - att objekten är framträdande medan personerna står i bakgrunden - kan det leda till DO-fokus. Några direkta stöd för en sådan tanke finns inte, även om det vore enkelt att testa med ett nytt experiment. Jag lämnar därför frågan obesvarad för framtida undersökningar.

\section{Slutsats}

De två experimenten visar således att hypoteserna verifierades. Barn tolkar inte kontrastiv betoning medan vuxna gör det. Om detta beror på att barn har ett mer begränsat arbetsminne än vuxna är svårt att avgöra eftersom detta experiment inte enbart utformades för att testa barns arbetsminne. En sak är dock klar, Reinharts (1999) tanke om att barn skulle gissa vid kontrastiv betoning finner inget stöd. Mitt resultat stöder snarare Musolino \& Lidz (under tryck) hypotes om att barn följer en strategi vid tolkandet av satser, och att denna strategi inte alltid behöver vara densamma som vuxna följer. Barnen i min studie följer en klar strategi vid tolkandet av fokusdomänen hos bara (DO-tolkning), en strategi som de applicerar både i det neutrala och det fokuserade villkoret. Även vuxna visade sig följa denna strategi i det neutrala villkoret och i viss mån ha svårt för att avvika från den i det fokuserade villkoret.

\section{(C) Christian Waldmann}

\section{Litteratur}

Bates, Elizabeth, Thal, Donna, Finlay, Barbara \& Clancy, Barbara. 2001. Early language development and its neural correlates. I Rapin, Isabella \& Segalowitz, Sid. (red.), Handbook of Neuropsychology, Vol. 8, Child Neurology, s. 525-592. Amsterdam: Elsevier.

Christophe, Anne \& Morton, John. 1998. Is Dutch native English? Linguistic analysis by 2months olds. Developmental Science, 1:2, s. 215-219.

Crain, Stephen \& Thornton, Rosalind. 1998. Investigations in universal grammar : a guide to experiments on the acquisition of syntax and semantics. Cambridge, Mass.: MIT Press.

Church, Kenneth Ward. 1987. Phonological parsing in speech recognition. Boston: Kluwer.

Dehaene-Lambertz, Ghislaine \& Houston, Derek M. 1998. Faster orientation latency toward native language in two-month-old infants. Language and Speech, 41:1, s. 21-43.

Diderichsen, Paul. 1946. Elementær dansk Grammatik. København: Gyldendal.

Dupoux, Emmanuel, Pallier, Christophe, Sebastian, Nuria \& Mehler, Jacques. 1997. A destressing 'deafness' in French? Journal of Memory \& Language, 36:3, s. 406-422.

Frazier, Lyn. 1987. Structure in auditory word recognition. I Frauenfelder, Uli H. \& Komisarjevsky Tyler, Lorraine. (red.), Spoken word recognition, s. 157-187. Cambridge, 
Mass.: MIT Press.

Gualmini, Andrea. 2003a. Some knowledge children don't lack. I proceedings från Boston university conference on language development, 28, s. 276-287.

Gualmini, Andrea. 2003b. Children do not lack some knowledge. University of Maryland Working Papers in Linguistics, 12, s. 49-74.

Gualmini, Andrea, Maciukaite, Simona \& Crain, Stephen. 2003. Children's insensitivity to contrastive stress in sentences with only. Penn Working Papers in Linguistics, 8:1, s. 87110.

Guasti, Maria Teresa. 2002. Language acquisition : the growth of grammar. Cambridge, Mass.: MIT Press.

Horn, Laurence R. 1989. A natural history of negation. Chicago: University of Chicago Press.

Jackendoff, Ray S. 1972. Semantic interpretation in generative grammar. Cambridge, Mass.: MIT.

Jusczyk, Peter W., Hirsh-Pasek, Kathy, Kemler Nelson, Deborah G., Kennedy, Lori J., Woodward, Amanda \& Piwoz, Julie. 1992. Perception of acoustic correlates of major phrasal units by young infants. Cognitive Psychology, 24:2, s. 252-293.

Lundström-Holmberg, Eva \& af Trampe, Peter. 1987. Elementär fonetik: en kurs $i$ artikulatorisk fonetik. Lund: Studentlitteratur.

MacWhinney, Brian. 2000. The database: The CHILDES project: tools for analyzing talk; v. 2. Mahwah, N.J. ; London: Lawrence Erlbaum.

Mcdaniel, Dana \& Maxfield, Thomas. 1992. Principle B and contrastive stress. Language acquisition, 2, s. 337-358.

Mehler, Jacques \& Christophe, Anne. 1995. Maturation and learning of language in the first year of life. I Gazzaniga, Michael S. (red.), The cognitive neurosciences, s. 943-954. Cambridge, Mass: MIT Press.

Mehler, Jacques, Dupoux, Emmanuel, Nazzi, Thierry \& Dehaene-Lambertz, Ghislaine. 1996. Coping with linguistic diversity: The infant's viewpoint. I Morgan, James L. \& Demuth, Katherine. (red.), Signal to syntax, s. 101-116. Mahwah, N.J.: Lawrence Erlbaum.

Miller, Karen, Hsiang-Hua, Chang, Schmitt, Cristina \& Munn, Alan. 2004. Children can use focal stress to construct quantity implicatures. Poster presenterad vid Generative Approaches to Language Acquisition - North America, 17-20 december, Honolulu, Hawaii.

Morgan, James L. 1986. From simple input to complex grammar. Cambridge, Mass.: MIT Press.

Musolino, Julien. 1998. Universal grammar and the acquisition of semantic knowledge: an experimental investigation into the acquisition of quantifier-negation interaction in English. Unpublished Ph.D. Dissertation. University of Maryland at College Park.

Musolino, Julien \& Lidz, Jeffrey. (under tryck). Why children aren't universally successful with quantification. Linguistics.

Musolino, Julien \& Lidz, Jeffrey. 2003. The scope of isomorphism: turning adults into children. Language acquisition, 11:4, s. 277-291. 
Mörnsjö, Maria. 1999. Theories on the assignment of focal accent as applied to Swedish. Working papers in Scandinavian syntax, 64, s. 37-78.

Nazzi, Thierry, Floccia, Caroline \& Bertoncini, Josiane. 1998a. Discrimination of pitch contours by neonates. Infant Behavior and Development, 21:4, s. 779-784.

Nazzi, Thierry, Bertoncini, Josiane \& Mehler, Jacques. 1998b. Language Discrimination by Newborns: Toward an Understanding of the Role of Rythm. Journal of Experimental Psychology: Human Perception and Performance, 24:3, s. 756-766.

Plunkett, Kim \& Strömqvist, Sven. 1992. The acquisition of Scandinavian languages. I Slobin, Dan I. (red.), The crosslinguistic study of language acquisition, s. 457-556. Hillsdale, NJ: Lawrence Erlbaum Associates.

Reinhart, Tanya. 1999. The processing cost of reference-set computation: guess patterns in acquisition. OTS Working Papers in Linguistics.

Strömqvist, Sven, Richtoff, Ulla \& Andersson, Anders-Börje. 1993. Strömqvist's and Richtoff's corpora : a guide to longitudinal data from four Swedish children. Göteborg: Göteborgs universitet.

Szendröi, Kriszta. 2003. Acquisition evidence for an interface theory of focus. I Van Kampen, Jacqueline \& Baauw, Sergio. (red.), Proceedings of Generative Approaches to Language Acquisition 2003. Utrecht: Netherlands Graduate School of Linguistics.

Trueswell, John C., Sekerina, Irina, Hill, Nicole M. \& Logrip, Marian L. 1990. The kindergarten-path effect: studying on-line sentence processing in young children. Cognition, 73, s. 89-134.

Wijk-Andersson, Elsie. 1991. Bara i fokus. En semantisk-syntaktisk studie av bara och dess ekvivalenter i nysvenskt skriftspråk. Uppsala: Institutionen för nordiska språk vid Uppsala universitet.

För kommentarer på denna artikel vill jag tacka Daniel Bergman och Gunilla Byrman. För kommentarer på en tidigare version av denna artikel vill jag tacka Lisa Christensen, Christer Platzack och forskarseminariet vid institutionen för nordiska språk vid Lunds universitet.

[1] Isomorfisk tolkning innebär att räckviddsförhållandet avspeglar den syntaktiska ytstrukturen, medan icke-isomorfisk innebär att räckviddsförhållandet inte följer den syntaktiska ytstrukturen.

[2] En isomorfisk tolkning av not... some är ogrammatisk och motsvarar den grammatiska tolkningen not... any. Barn föredrar således en tolkning av The detective didn't find some guys som inte existerar i vuxenspråket.

[3] Inom barnspråksforskningen anges ett barns ålder med ett särskilt notationssystem, t.ex. 2;3.20. Första siffran betecknar år, andra siffran månader och sista siffran dagar. Ett barn i åldern 2;3.20 är således 2 år, 3 månader och 20 dagar gammalt. Ofta används bara de två första siffrorna. Jag kommer i fortsättningen att använda detta notationssystem.

[4] Att bara är mittfältsplacerat innebär att det förekommer i positionen A1 enligt

Diderichsens (1946) satsschema.

[5] Jag vill rikta ett särskilt tack till Daniel Bergman för hans skådespelartalanger under materialinsamlingen. Jag vill även tacka de vuxna informanterna samt personal och barn på följande förskolor i Växjö för deras medverkan i studien: Blåbärsstället, Solrosen,

Näckrosen och Förskoleklass A på Högstorpsskolan. 